\title{
Effectiveness of telephone-based screening and triage during COVID-19 outbreak in the promoted primary healthcare system: a case study in Ardabil province, Iran
}

\author{
Nazila NeJhaddadgar ${ }^{1} \cdot$ Arash Ziapour $^{2}$ (D) $\cdot$ Ghader Zakkipour $^{3} \cdot$ Jaffar Abbas $^{4} \cdot$ Mitra Abolfathi $^{5} \cdot$ Masoud Shabani $^{6}$
}

Received: 4 June 2020 / Accepted: 3 November 2020 / Published online: 13 November 2020

(C) Springer-Verlag GmbH Germany, part of Springer Nature 2020

\begin{abstract}
Aims Screening services for early detection of patients is one of the important capabilities of the health system with a proper referral system. In the crisis of respiratory infection of Covid-19, screening based on symptoms is one of the key measures. The aim of the current study was to evaluate the telephone-based screening and triage services in the promoted primary healthcare system with regard to the Covid-19 outbreak, in terms of reducing unnecessary referrals to the hospital.

Methods This is a descriptive cross-sectional study conducted in two stages on 1,406,635 households during March/April 2020 in Ardabil province for screening and early detection of Covid-19 disease. In the first stage, conducted by trained healthcare providers through telephone, individuals suspected of Covid-19 were identified. In the second stage, the individuals were referred to the second level of service in comprehensive healthcare centers (16- or 24-h centers) for clinical evaluation by a physician.

Results The results showed that before establishing a screening and triage system for patients in comprehensive healthcare centers, all patients were referred directly to the hospital, while after the implementation of the program, a significant reduction in hospital visits was observed and a large number of patients undertook the care and triage services in comprehensive healthcare centers.

Conclusion The use of a grading system in referring patients with suspected cases, triage of patients according to symptoms at the comprehensive health centers, and activation of home isolation were the most important factors in reducing the burden of unnecessary referrals of patients to the hospital.
\end{abstract}

Keywords Screening $\cdot$ Triage $\cdot$ Covid-19 $\cdot$ Comprehensive health centers

\section{Introduction}

Acute respiratory infection caused by Covid-19 is one of the diseases with high transmission in the world today (Lai et al.
2020; WHO 2020). Due to its rapid transmission, the number of visits to hospitals and medical centers is increasing sharply (Wang et al. 2020). There is a strong relationship between the capacity of a health system and the mortality rate of patients

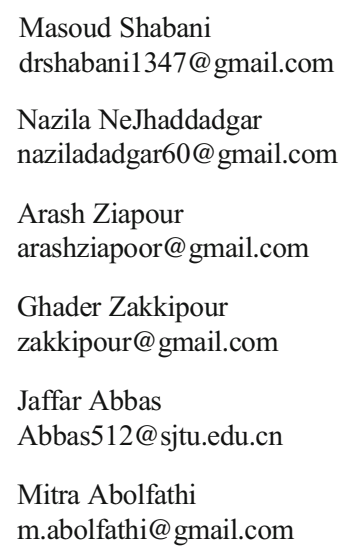

1 Department of Health Promotion and Education, Ardabil University of Medical Sciences, Ardabil, Iran

2 Health Education and Health Promotion, Health Institute, Kermanshah University of Medical Sciences, Kermanshah, Iran

3 Fellowship of National Health \& Treatment Network Management, Ardabil University of Medical Sciences, Ardabil, Iran

4 Antai College of Economics and Management/School of Media and Communication, Shanghai Jiao Tong University, Shanghai, China

5 Department of Health Education and Health Promotion, School of Public Health, Iran University of Medical Sciences, Tehran, Iran

6 Fellowship of National Health \& Treatment Network Management, Department of Community Dentistry, School of Dentistry, Ardabil University of Medical Sciences, Ardabil, Iran 
(Ji et al. 2020). The use of all the capacities of a health system in times of health crisis and epidemic conditions is a key approach to solving a problem. An epidemic can be controlled through a powerful health system, justice in the health system, and people's participation - i.e., It is controllable. In our country, Iran, the health system has a strong infrastructure in controlling diseases; the establishment of a health network for primary healthcare since 1985 has had good results in controlling infectious diseases and has provided health facilities to all layers of the population (Yoosefi Lebni et al. 2020; Pilehrodi 1997; Pileroudi 1999).

To make this system dynamic, since 2005 , the family physician program and referral system have been added to it. In this health system, all services are leveled and healthcare providers and health workers as first-level forces do services at the first level. At the second level, the physicians are considered as second-level forces in comprehensive health service centers; this has prevented unnecessary referrals of patients and clients to hospital (Naseriasl et al. 2018; Ministry of Health and Medical Education 2009). In confronting a health crisis, the use of a referral system is a key and effective measure (WHO 1999; Pringle et al. 2018).

Performing primary electronic services (e-screening) to identify patients early is one of the most important capabilities of the health system with the appropriate referral system (Azamar-Alonso et al. 2019). In the crisis of respiratory infection of Covid-19, screening based on symptoms is one of the key measures. This measure is performed in the health system by trained caregivers and health workers at the first level and can prevent unnecessary visits to the hospital (Ge et al. 2020). If screening and triage services are not provided in comprehensive healthcare centers and attention id not paid to medical services and the referral system in the crisis caused by the outbreak of acute respiratory infection of Covid-19, all patients with suspicious, mild, severe, and critical symptoms will be referred directly to the hospital. On the one hand, this causes inappropriate and incorrect occupation of the hospital's capacity to treat patients in need; on the other hand, it wastes a powerful system in the country, namely the family physician system and the referral system in healthcare networks (Mahase 2020). For this reason, screening at the first level of service is performed telephonically, based on the symptoms of the disease, finding suspicious cases and referring them to the Comprehensive Health Services Center (second level of service). At the second level, performing triage services is a basic approach in the country's health system to manage respiratory infection of Covid-19 for the proper use of hospital services for people in acute and critical illness (Reeves et al. 2020).

With regard to the mentioned cases, the current situation in the region, the very widespread epidemic of this virus, and the importance of the disease in Ardabil and its prevalence in this region, we should conduct a study on the reduction of the burden of referral to hospital with the approach of establishing initial telephone screening at the first level. Consequently, we should activate comprehensive healthcare centers as the goalkeeper of a dynamic health system by establishing triage services for Covid-19 respiratory infection and activating the referral system.

\section{Methods}

This research is a descriptive cross-sectional study conducted in two stages on 1,406,635 eligible people (over 30 years old) in Ardabil province, Iran, for screening and early detection of Covid-19 disease in rural and urban areas for about 1 month (during March/April 2020). In this study, preliminary information on eligible individuals was collected from the electronic health system, and additional information on the symptoms of Covid-19 was obtained through telephone calls from healthcare providers.

Stage 1: At the first level of service, healthcare givers provide their questionnaire (this questionnaire was designed by the Ministry of Health) based screening through telephone (healthcare providers made phone calls to people over the age of 30 whose personal information was recorded on the e-health system, and these people were asked whether they had aany signs of Covid19; this call took about $8-10 \mathrm{~min}$ ). At this stage, we evaluated households with symptoms of sore throat, fever, dry cough, chills, shortness of breath, contact with a person with Covid-19, infected person among the family members, presence of a high-risk person, or having an underlying disease in the family, and recorded the information obtained online in the national electronic health information system. Then, if there was a person in the family suspected of having Covid-19, he/she would be screened for the second level.

Stage 2: At this stage, for clinical evaluation by a physician, people suspected of having Covid-19 disease were referred to the second level of service in comprehensive health services centers (16- or 24-h centers). At this stage, clients were evaluated in terms of having any symptoms of chills, sore throat, dry cough, shortness of breath or hypoxia, pulmonary infiltration, chloroquine usage inhibition, history of contact with a person suspected of Covid-19, having any of the symptoms (fever, dry cough, shortness of breath, chills) in family members, presence of high-risk person at home, and lung X-ray imaging. At this stage, the results were recorded online in the national electronic health information system. At the second level of service, triage service was done for the persons referred by center physician, and the clients received related services in terms of results. (We have shown the screening and referral stages in the following algorithm 1). 
Table 1 Preliminary evaluation results by healthcare providers and health workers (first level of service)

\begin{tabular}{llll}
\hline Symptoms & $\begin{array}{l}\text { With } \\
\text { symptoms }\end{array}$ & $\begin{array}{l}\text { Total } \\
\text { number }\end{array}$ & Percentage \\
\hline Sore throat & 7271 & $1,406,635$ & 0.52 \\
Fever & 1736 & $1,406,635$ & 0.12 \\
Dry cough & 9827 & $1,406,635$ & 0.70 \\
Chills & 1243 & $1,406,635$ & 0.09 \\
Shortness of breath & 2449 & $1,406,635$ & 0.17 \\
History of contact with a person suspected of Covid-19 disease & 4425 & $1,406,635$ & 0.31 \\
Does anyone in the family have one of the symptoms (fever, dry & 5181 & $1,406,635$ & 0.37 \\
$\quad$ cough, shortness of breath and chills?\}) (Infected person in the & & & \\
$\quad$ family) & & $1,406,635$ & 13.67 \\
Is there anyone in the family who is at high risk for Covid-19 disease? & 192,222 & & \\
$\quad$ (Having an underlying disease) & & & \\
\hline
\end{tabular}

This has been one of the basic approaches to the use of the leveling and referral system in the country's health system to manage respiratory infection caused by Covid19 for the proper use of hospital services for people in acute and critical illness. We conducted this study after receiving the necessary licenses from the deputy for Research and Technology of Ardabil University of Medical Sciences (IR.ARUMS.REC.1399.089). We obtained conscious verbal consent from all participants in the survey prior to registration; we assured participants of confidentiality of information.

\section{Results}

Out of a total of $1,406,635$ people screened by caregivers and health workers in the first level of service, 224,354 people (15.94\%) were suspected of having Covid-19 disease (they had at least one of the symptoms mentioned in Table 1). They were referred to the second level in the comprehensive health service centers (16- or 24-h selected centers of Ardabil University of Medical Sciences) (Table 1). According to the evaluation made by the physician, 9017 people $(4.01 \%)$ with symptoms were confirmed. The results of the physician's evaluation at the second level are reported in Table 2. According to the results of this evaluation, appropriate measures were presented (Tables 3 and 4). In Fig. 1, the number of people referred to the hospital from 5 to 25 March 2019 shows that this date was before the implementation of the telephonic screening plan and household triage by the doctor of comprehensive health centers. Figure 2 covers the period of March 17 to April 4; the figure shows a decrease in the number of visits.

The collected data during 17 days before intervention showed that $88.1 \%$ of patients were directly referred to hospital, and that after intervention through activation of the referral system, telephone-based screening, and triage services in primary healthcare system, about $57.2 \%$
Table 2 Results of evaluation by physician (second level of service)

\begin{tabular}{lllr}
\hline Symptoms & $\begin{array}{l}\text { With } \\
\text { symptoms }\end{array}$ & $\begin{array}{l}\text { Total } \\
\text { number }\end{array}$ & Percentage \\
\hline Chills & 1020 & 9017 & 11.31 \\
Sore throat & 2441 & 9017 & 27.07 \\
Dry cough & 2711 & 9017 & 30.07 \\
Shortness of breath or hypoxia & 397 & 9017 & 4.40 \\
Is lung imaging available? & 4 & 9017 & 0.04 \\
Does he/she have pulmonary infiltration? & 3 & 9017 & 0.03 \\
Is he/she inhibited to take hydroxychloroquine sulfate tablets? & 5 & 9017 & 0.06 \\
History of contact with a person suspected of Covid-19 disease & 634 & 9017 & 7.03 \\
Does anyone have any of the symptoms? & 731 & 9017 & 8.11 \\
Is anyone in the family in the high-risk group for Covid-19 & 1071 & 9017 & 11.9 \\
$\quad$ disease? & & & \\
\hline
\end{tabular}


Table 3 Results of actions done by the physician in terms of symptoms (second level of service)

\begin{tabular}{lllr}
\hline Physician's actions & Age group (years old) & Number & Percentage \\
\hline Resting at home & $1-100$ & 2744 & 30.4 \\
Starting treatment with a single medication & $1-100$ & 41 & 0.5 \\
Active daily follow-up by a healthcare provider & $1-100$ & 2259 & 25.1 \\
Referring to the selected hospital & $1-100$ & 400 & 4.4 \\
Brochure training and presentation & $1-100$ & 3563 & 39.5 \\
It is not prescribed due to the sensitivity of the drug & $1-100$ & 5 & 0.1 \\
Providing special care during pregnancy & $1-100$ & 3 & 0.0 \\
Stabilization of the mother and fetus' condition & $1-100$ & 2 & 0.0 \\
\hline
\end{tabular}

of patient were directly referred to hospital. In summary, using the latter approach we had a $30 \%$ reduction with referrals.

\section{Discussion}

The history of human life has seen several major epidemics. Many people have died of these epidemics or pandemics. In the present century, we have seen major epidemics such as SARS, influenza H1N1, Zika, Ebola, and now Covid-19 (Lehmann and Sanders 2007). Scientific evidence suggests that the management of large epidemics requires a capable referral system, public participation alongside government, and justice. These measurements are necessary for the reduction of disease burden, management, and ultimately control (Fort et al. 2012). In the present study, the results showed that using the ability of health workers and referring real patients to care in hospital is a result of strengthening the cooperation of the healthcare system.

The experience of controlling epidemics has shown that strengthening the participation of hospitals and health centers in the form of a targeted referral system is a very effective step in controlling large epidemics (Van Lerberghe 2008). Implementation of health protocols in line with this great goal is very important in the crisis caused by the outbreak of the acute respiratory infection of Covid-19. Hospital services should be provided for people with special problems, so that those who do not need to be hospitalized are not referred to hospital, which is one of the centers of infection. In the

Table 4 Referring of patients to the hospital before and after introducing

\begin{tabular}{llll}
\hline Variable & $\begin{array}{l}\text { Type of patients } \\
\text { before } \\
\text { introducing }\end{array}$ & $\begin{array}{l}\text { Type of patients } \\
\text { after introducing }\end{array}$ & $\begin{array}{l}\text { Reduction } \\
\text { in patients }\end{array}$ \\
\hline $\begin{array}{l}\text { During } \\
\text { March/April 2020 }\end{array}$ & $5335(88 / 1 \%)$ & $7903(57 / 2 \%)$ & $2568(30 / 9)$ \\
\hline
\end{tabular}

meantime, primary screening at the level of a service and then triage of patients in comprehensive healthcare centers and the establishment of a strong referral system is very crucial so that hospital services are not wasted (McCollum et al. 2016). The results of the study showed that the use of a series of levels in the referral of suspected cases of the disease, and triage of patients according to symptoms, was one of the most important factors in reducing the burden of patients' visits to medical centers. On the other hand, in addition to reducing the burden of patient visits by being allowed to remain at home and maintaining physical distance with family members of patients, the suspected cases were under the control of the health system (Shaker et al. 2020).

Using the capabilities of family physician and referral system by providing effective screening and triage services in the first level of service can prevent unnecessary referral of patients suspected of Covid-19 to the hospital. From this perspective, the system's ability to deal with acute and critical cases will be stored and in cases where the actual prescription is hospitalization, this capability will be appropriate.

The results also showed that before establishing a screening and triage system for patients in comprehensive healthcare centers, all patients were referred directly to the hospital (Fig. 1). However, the hospital should not be a substitute for other health facilities, and in fact, the hospital is a place for patients with acute emergencies. This approach not only reduced the number of visits to the hospital, but also reduced the

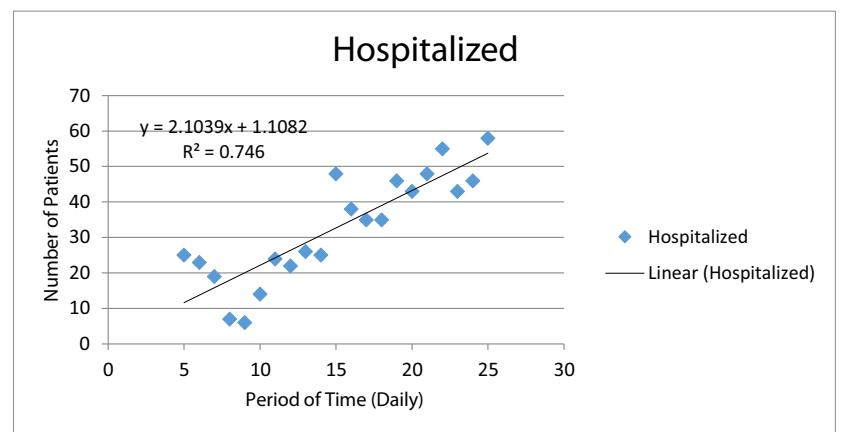

Fig. 1 Clients of the hospital due to Covid-19 from 5 to 25 March. This figure shows the high number of hospital visits 


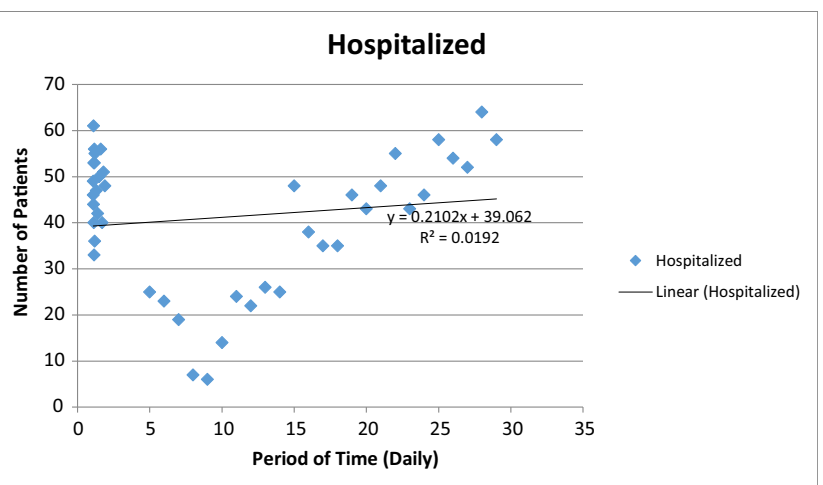

Fig. 2 Clients of the hospital due to Covid-19 from March 17 to April 4. In this figure, an intervention has been performed that has reduced the burden of hospital visits and has led people with symptoms to health centers

likelihood of transmission and spread of the disease due to reduced distance and contact (WHO 2020; Shojaeezadeh 2013). In general, there is a strong interest among people to go to the hospital after their first encounter with the healthcare system, and if this process is not corrected, the first level centers of a service will easily lose their value (Ebadi Fard Azar 2011).

\section{Conclusion}

The use of a grading system in referring patients with suspected cases, triage of patients according to symptoms at the comprehensive health centers, and activation of home isolation were the most important factors in reducing the burden of unnecessary referrals of patients to the hospital.

Acknowledgments Our grateful thanks go to all participants in the present study, and we would like to express our deepest gratitude to the Deputy for Research in Ardabil University of Medical Sciences because of their financial support with regard to this project.

\section{Compliance with ethical standards}

Ethics approval and consent to participate This study was drawn from a research project (No. IR.ARUMS.REC.1399.089) sponsored by the Deputy of Research and Technology at AUMS.

Conflict of interest The authors declare that they have no conflict of interest.

\section{References}

Azamar-Alonso A, Costa AP, Huebner LA, Tarride JE (2019) Electronic referral systems in health care: a scoping review. Clinicoecon Outcomes Res 11:325-332. https://doi.org/10.2147/CEOR. S195597 eCollection 192019

Ebadi Fard Azar F (2011) Health service principles. 2nd ed. Gisom. pp $63-81$
Fort MP, Grembowski D, Heagerty P, Lim SS, Mercer MA (2012) Evaluation of a demonstration primary health care project in rural Guatemala: the influence of predisposing, enabling and need factors on immunization coverage, equitable use of health care services and application of treatment guidelines. Int Health 4(3):220-228

Ge Y, McKay BK, Sun S, Zhang F, Handel A (2020) Assessing the impact of a symptom-based mass screening and testing intervention during a novel infectious disease outbreak: the case of COVID-19. MedRxiv 12:1-5. https://doi.org/10.1101/2020.02.20.20025973

Ji Y, Ma Z, Peppelenbosch MP, Pa Q (2020) Potential association between COVID-19 mortality and health-care resource availability. Lancet Glob Health 8(4):e480. https://doi.org/10.1016/S2214109X(20)30068-1

Lai CC, Wang CY, Wang YH, Hsueh SC, Ko WC, Hsueh PR (2020) Global epidemiology of covid-19 virus disease 2019: disease incidence, daily cumulative index, mortality, and their association with country healthcare resources and economic status. Int $\mathrm{J}$ Antimicrob Agents 55(4):105946-105952. https://doi.org/10.1016/j. ijantimicag.2020.105946

Lehmann U, Sanders D (2007) Community health workers: what do we know about them. The state of the evidence on programmes, activities, costs and impact on health outcomes of using community health workers, vol 58. World Health Organization, Geneva, pp 142

Mahase E (2020) Covid-19 virus: home testing pilot launched in London to cut hospital visits and ambulance use. BMJ 368:m261. https:// www.bmj.com/content/368/bmj.m621

McCollum R, Gomez W, Theobald S, Taegtmeyer M (2016) How equitable are community health worker programmes and which programme features influence equity of community health worker services? A systematic review. BMC Public Health 16(1):419-442. https://doi.org/10.1186/s12889-016-3043-8

Ministry of Health and Medical Education (2009) Family physician instruction. Version 9. Ministry of Health and Medical Education, Iran, pp 4-102

Naseriasl M, Janati A, Amini A, Adham D (2018) Referral system in rural Iran: improvement proposals. Cad Saude Publica 34(3):e00198516. https://doi.org/10.1590/0102-311x00198516

Islamic Republic of Iran (1999) Human Development Report of the Islamic Republic of Iran. Islamic Republic of Iran Plan and Budget Organization, Tehran (original in Farsi). https://www.ilo. org/dyn/travail/docs/884/Human\%820Development\%820Report\% 820-\%820Islamic\%820Republic\%820of\%820Iran\%820-\%201999. pdf

Pilehrodi S (1997) Management services on district health network. Iran Ministry of Health, Tehran [In Persian]

Pileroudi S (1999) Township network health and treatment. UNICEF, Iran, pp 12-13

Pringle JL, Kelley DK, Kearney SM, Aldridge A, Dowd W, Johnjulio W, Lovelace J (2018) Screening, brief intervention, and referral to treatment in the emergency department. MedCare 56(2):146-152. https://doi.org/10.1097/MLR.0000000000000859

Reeves JJ, Hollandsworth HM, Torriani FJ, Taplitz R, Abele S, Tai-Seale M, Longhurst CA (2020) Rapid response to COVID-19: health informatics support for outbreak management in an academic health system. J Am Med Inform Assoc 9:1-7. https://doi.org/10.1093/ jamia/ocaa1037

Shaker MS, Oppenheimer J, Grayson M, Stukus D, Hartog N, Hsieh EW, Kim H (2020) COVID-19: pandemic contingency planning for the allergy and immunology clinic. J Allergy Clin Immunol Pract 8: 1477-1488. https://doi.org/10.1016/j.jaip.2020.1403.1012

Shojaeezadeh D (2013) Health service principles. 6th ed. Samt. pp 80-96

Van Lerberghe W (2008) The World Health Report 2008: primary health care (now more than ever). World Health Organization, Geneva 
Wang CJ, Ng CY, Brook RH (2020) Response to COVID-19 in Taiwan: big data analytics, new technology, andproactive testing. JAMA 323(14):1341-1342. https://doi.org/10.1001/jama.2020.3151

WHO (1999) https://www.who.int/docs/default-source/covid-19viruse/ situation-reports/20200229-sitrep-40-covid-19.pdf?sfvrsn= 849d0665_2. Accessed 29 Feb 2020

WHO (2020) Assessment of risk factors for corona virus disease 2019 (COVID-19) in health workers: protocol for a case-control study 26 May 2020. World Health Organisation, Geneva
Yoosefi Lebni J, Abbas J, Moradi F, Salahshoor M, Chaboksavar F, Irandoost SF, Ziapour, A (2020) How the COVID-19 pandemic effected economic, social, political, and cultural factors: a lesson from Iran. Int J Soc Psychiatry 2 July 2020 [Letter] https://doi.org/ 10.1177/0020764020939984

Publisher's note Springer Nature remains neutral with regard to jurisdictional claims in published maps and institutional affiliations. 